\title{
Microarray analysis of the expression profile of IncRNAs reveals the key role of IncRNA BC088327 as an agonist to heregulin-1 $\beta$-induced cell proliferation in peripheral nerve injury
}

\author{
HOULEI WANG, JINGPING WU, XINCHAO ZHANG, LEI DING and QINGMIN ZENG \\ Department of Orthopedics, Jinshan Hospital of Fudan University, Shanghai 201508, P.R. China
}

Received October 9, 2016; Accepted November 24, 2017

DOI: $10.3892 /$ ijmm.2018.3571

\begin{abstract}
Heregulin-1 $\beta$ is capable of promoting the nerve regeneration of acellular nerve allografts with skin-derived precursor differentiated Schwann cell (SC) therapy in peripheral nerve injury. Long non-coding RNAs (lncRNAs) serve important roles in the regulation of gene transcription and translation in multiple biological processes, but its association with the repair of peripheral nerve injury is unexplored. Therefore, in the present study, the aim was to identify novel indicators for peripheral nerve injury, and to detect whether there is an association between IncRNA expression and the treatment effect of heregulin-1 $\beta$ on this disorder. The expression status of lncRNAs and mRNAs in a well-built rat model with sciatic nerve injury was investigated using microarray assays. Based on the results of the microarray assays and quantitative polymerase chain reaction validation, it was inferred that lncRNA BC088327 was upregulated to the largest extent among all the lncRNAs. According to these findings, the role of BC088327 in peripheral nerve injury was further assessed by detecting the cell viability, cell cycle and apoptosis in a hypoxic SC cell model after suppressing the expression of BC088327 using specific small interfering RNA. Based on the results of the lncRNA microarray assay, $805 \operatorname{lncRNAs}$ were significantly differentially expressed, among which, 323 lncRNAs were upregulated and 482 lncRNAs were downregulated. Based on the results of the mRNA microarray assay, 1,293 lncRNAs were significantly differentially expressed, including 603 upregulated and 690 downregulated lncRNAs. Moreover, knockdown of lncRNA BC088327 suppressed cell
\end{abstract}

Correspondence to: Professor Qingmin Zeng, Department of Orthopedics, Jinshan Hospital of Fudan University, 1508 Longhang Road, Shanghai 201508, P.R. China

E-mail: doctorzqm@outlook.com; qingminzeng1703@163.com

Abbreviations: 1ncRNAs, long non-coding RNAs; SCs, Schwann cells; SKPs, Schwann cells isolated from skin-derived precursors; ANA, acellular nerve allograft

Key words: peripheral nerve injury, long non-coding RNA, heregulin-1 $\beta$, Schwann cells, acellular nerve allograft, BC088327 viability and induced cell apoptosis and S-phase cell cycle arrest in the SCs. In conclusion, expression profile changes of lncRNAs in peripheral nerve injuries were closely associated with treatment with heregulin-1 $\beta$. IncRNA BC088327 may play a synergistic role with heregulin-1 $\beta$ in repairing peripheral injury, which has the potential be a biomarker for the detection of peripheral injury and a medical target for the development of therapeutic modalities.

\section{Introduction}

Peripheral nerve injury is a common disorder of the nervous system and affects $\sim 13$ to 22 individuals per 100,000 each year, which has become a severe public health issue worldwide (1). Furthermore, the amount of patients suffering from peripheral nerve injuries is expected to increase. It is generally recognized that the peripheral nervous system is different from the central nervous system in that nerve regeneration will be activated if peripheral neurons are damaged (2). However, even with the instinctive regeneration capability of peripheral neurons, efficient therapy for peripheral nerve injury remains unavailable. Thus, it is necessary to develop novel and effective therapies to promote axon regeneration after peripheral nerve injury. In order to fulfill such a purpose, the comprehensive investigation of the changes in lesion neurons and identification of the biological molecules that are responsible for neuronal survival and axonal regeneration demands a prompt solution.

The intrinsic regenerative capacity of a peripheral nerve is always activated after injury to that nerve. Generally, this regeneration process depends on axonal degeneration, phagocytosis of axonal debris, and secretion of trophic factors and cytokines by Schwann cells (SCs) (3). Among all these factors important to the regeneration of peripheral neurons, SCs, originating from the neural crest, serve a determinant role in the intrinsic regenerative capacity of the peripheral nervous system due to its high abundance and potency in repairing the lesion sites in this location (2). In previous studies, it has been shown that SCs can be employed for transplants in the spinal cord for nerve repair $(4,5)$. Moreover, SCs are able to maintain the peripheral nerve fibers. Malfunctions of SCs are reported to be associated with peripheral nerve injuries and various neuropathy conditions, including hereditary, metabolic and inflammatory conditions (6,7). Currently, skin-derived precursors (SKPs) are an excellent resource for the isolation of SCs that can be 
utilized as outstanding cell models suited for investigation of the mechanism involved in nerve regeneration. Additionally, SKP-derived SCs (SKP-SCs) have been explored for their potential application in the scenario of peripheral nerve injury (8). With the exception of the application of SKP-SCs alone, only concatenated application of the acellular nerve allograft (ANA) injection with SKP-SC has been presented as a better modality for nerve repair compared with intrinsic regeneration $(9,10)$. In addition, in our previous studies, it was found that injection of heregulin-1 $\beta$, a type of pleiotropic growth factor or neuregulin, further promotes the outcome of reinnervation by the ANA with SKP-SC therapy via regulation of neuronal and glial development $(11,12)$. However, even though the treatment of peripheral nerve injuries with heregulin-1 $\beta$ achieves a notable outcome, the underlying mechanism through which heregulin-1 $\beta$ facilitates ANA with SKP-SC therapy remains unclear.

Recently, multiple studies have suggested that the mechanism associated with injuries to the peripheral nerves depends on the function of various non-coding RNAs (13-16). Among which, long non-coding RNAs (IncRNAs) have been shown to be involved in various biological processes and disease pathologies (17). Considering the promising effect of heregulin-1 $\beta$ in treating peripheral nerve injures and the multiple functions of IncRNA, it is reasonable to investigate the association between these two factors in a peripheral nerve injuries model. Furthermore, although a number of lncRNAs have been identified to serve key roles in gene transcription and translation in mammalian cells (18), few lncRNAs that may be associated with the repair of peripheral nerve injuries have been found.

Therefore, in the present study, the association between IncRNA expression profiles and nerve repair was detected using microarray assays in a well-built rat model with sciatic nerve injury. The ANA injection with SKP-SC and the ANA injection with SKP-SC plus heregulin-1 $\beta$ were used to treat the sciatic nerve injury. Moreover, the specific functions of lncRNA BC088327 in peripheral nerve injuries were further assessed using cell viability, cell cycle and apoptosis assays in a hypoxic SC model. The findings outlined in the present study demonstrated that the expression profile of lncRNAs was closely associated with the presence of heregulin-1 $\beta$, and that lncRNA BC088327 may play a synergistic role with heregulin- $1 \beta$ in repairing peripheral nerve injury.

\section{Materials and methods}

Cell isolation and culture. SKPs were generated from the dermis of postnatal day Wistar rats and cultured routinely according to a protocol described by previous studies $(6,19)$. The isolated SKPs were identified with the staining of nestin and fibronectin on the cell surface. Cultured SKP-SCs were fixed in ice-cold absolute methanol for $20 \mathrm{~min}$ and blocked with $1 \%$ goat serum for $1 \mathrm{~h}$. Cells were then incubated with mouse monoclonal anti-Nestin (1:100; cat. no. ab6142; Abcam, San Francisco, CA, USA), rabbit polyclonal anti-fibronectin (1:100; cat. no. ab2413; Abcam) at $4^{\circ} \mathrm{C}$ overnight and visualized with anti-rabbit IgG $(\mathrm{H}+\mathrm{L}) \mathrm{F}\left(\mathrm{ab}^{\prime}\right) 2$ Fragment (Alexa Fluor 488 conjugate) (1:500; cat. no. 4412; Cell Signaling Technology, Danvers, MA, USA) and anti-mouse IgG $(\mathrm{H}+\mathrm{L})$ $\mathrm{F}\left(\mathrm{ab}^{\prime}\right) 2$ Fragment (Alexa Fluor 488 conjugate) (1:500; cat. no. 4408; Cell Signaling Technology). SCs were induced by incubating SKPs on poly-D-lysine-laminin-coated culture dishes (Corning, Inc., Corning, NY, USA) in Dulbecco's modified Eagle's medium (DMEM)/F12, with $4 \mathrm{mM}$ forksolin, 10 ng/ml heregulin-1 $\beta$ (cat. no. 4711-50; Biovision, Inc., Milpitas, CA, USA) and $1 \% \mathrm{~N}_{2}$ supplement (Gibco; Thermo Fisher Scientific, Inc., Waltham, MA, USA) for 1 week. Thereafter, cells appearing to have bipolar SC morphology under phase-contrast microscopy were isolated with cloning cylinders and expanded in the same medium until $>95 \%$ purity was achieved (6), and then identified by p75NGFR and S100- $\beta$ staining, as previously described (12).

ANAprocedure.A total of 20 adultmale SDrats (weight,200-250 g; Shanghai SLAC Laboratory Animal Co., Ltd., Shanghai, China) were anesthetized with chloral hydrate $(350 \mathrm{mg} / \mathrm{kg})$ and subjected to sciatic nerve transection in order to mimic peripheral nerve injury, as previously described (12). Rats were maintained under SPF conditions including a $12 \mathrm{~h}$ light/12 h dark cycle, temperature of $20-22^{\circ} \mathrm{C}$, and sterilized water and food. The rats were then treated with ANAs, as described in a previous study (12). All surgical procedures were performed bilaterally. Following the skin incision and a gluteal splitting incision, the sciatic nerve and its branches were exposed bilaterally. With the aid of a surgical microscope, the sciatic nerve $(20 \mathrm{~mm})$ was severed and removed closed to the obturator tendon in the mid-thigh. To prepare the ANA, the 20-mm sciatic nerve was rinsed with Hank's balanced salt solution (HBSS) and frozen in liquid nitrogen for $2 \mathrm{~min}$ following a 2-min rewarming period twice, and then stored in liquid nitrogen. At 1 day prior to transplantation, the ANA was incubated with $2 \mathrm{U} / \mathrm{ml}$ chondroitinase $\mathrm{ABC}$ or phosphate-buffered saline (PBS) for $16 \mathrm{~h}$ at $37^{\circ} \mathrm{C}$, then washed 2 times with HBSS and stored at $0^{\circ} \mathrm{C}$.

Animal care and surgery. The study was approved by the Institutional Animal Care and Use Committee of Fudan University (Shanghai, China). Rats were maintained under SPF conditions including a $12 \mathrm{~h}$ light $/ 12 \mathrm{~h}$ dark cycle, temperature of 20-22 $2^{\circ}$, and sterilized water and food. Recipient rats were divided into the ANA+SKP-SC-treated group (control group, $n=8$ ) and the ANA+SKP-SC+heregulin-1 $\beta$-treated group (experimental group, $n=8$ ), and underwent exposure of the right sciatic nerve. The recipient's nerve was transected at $5 \mathrm{~mm}$ proximal to the sciatic trifurcation and $15 \mathrm{~mm}$ of nerve was removed under a surgical microscope, as described in our previous study (12). For the two groups, $3 \mathrm{ml}$ of $2 \times 10^{6}$ cells $/ \mathrm{ml}$ SKP-SCs were injected into the ANA at the proximal end and at the distal end $3 \mathrm{~mm}$ from the anastomosis, respectively, using a micro-injector under an SXP-10 microscope at X10 magnification (Shanghai Medical Equipment Works Co., Ltd., Shanghai, China). Additionally, for the experimental group, $500 \mathrm{ng} / \mathrm{ml}$ heregulin- $1 \beta(3 \mathrm{ml})$ was injected into the ANA. At the end of the 8th week, the sciatic nerve was harvested en bloc $\sim 3 \mathrm{~mm}$ proximal and $\sim 4 \mathrm{~mm}$ distal to the interposed graft. The nerves were stored at liquid nitrogen and transferred to $\mathrm{a}-80^{\circ} \mathrm{C}$ fridge for the downstream application.

Microarray assays for differentially expressed lncRNA and $m R N A$ screening. The collected tissues were treated with TRIzol (Invitrogen; Thermo Fisher Scientific, Inc.) and the total RNAs were purified following the manufacturer's instructions. The integrity of the purified RNAs was checked with 
Table I. Primers used in qauntitative polymerase chain reaction analysis.

\begin{tabular}{|c|c|c|}
\hline Seqnames & Forward primer & Reverse primer \\
\hline ВС086339 & CAGCGGGAGGCTCATACTACAT & GGCTCCACAGCAGGAGACAA \\
\hline XR_007612 & ATGTTCCAGATCCCGTACCA & TCTTCTAGTGTTTCCCTAAGTTTC \\
\hline uc.19+ & AATCGCATTACTGCCCTTG & CTTGGGCTCTTAGCGTCTTA \\
\hline DQ203294 & AGAATCGGCACGAGGACCAA & TGAAGCCAGGCATACTGAAC \\
\hline ВC088327 & ATGAATGTGGAAATCGGAAAC & TTGGTAGGCTTGTCAGGGTC \\
\hline uc.184+ & TTCCAACAGTGAACATTTTTAGG & GAGATATCCCGTCAGTGAAAAG \\
\hline uc.75- & CCAAAACACAATAAATGCTCTTCT & TTTATGTGGCTCATTTTATATTTCC \\
\hline S56464 & АССТCTTAGTGGGTTATTGGC & TGGCTAACATCCTGGGTGAG \\
\hline uc.366- & CCGTCAAGTCTGCAAGGTCTC & GGCAAGTCATTTATTATGGGTTCT \\
\hline uc. $173+$ & TAATAAATGACTTGCCTCCTCG & ATGCAGCAATAACTTAGTTCACAC \\
\hline uc.10- & TGAGTGTAGAGGAGCAGAGGC & AAGGTACTGCGTGCATGAATA \\
\hline uc.456- & AAGATGACTGCCTTTCCTGAT & TGTCTAACCCTTGGAATCCTC \\
\hline uc.128- & TACCAGTCCTGTCGGTTGC & CCACAGAGCGGAAGTTGAT \\
\hline D26496 & GGAGCACGGCTATCACAGA & CTAGTGAATCAAGTGGAGGGAG \\
\hline uc.298- & TTTAACAGTGGTTTTTCTTTTTTG & CAGAAGAAAACTGTTGGGTGG \\
\hline uc.28- & TGAACAGGAATTAAGAATAAAGCTG & GCGGGAACTACTCTGACAACA \\
\hline uc.325- & TGAGGCAGCGCATCGTG & TGTCACAGGGCCGCACA \\
\hline uc.299- & CAGCAATCTTACCATGAGGTGT & CTTTCCCGAAGGGTTATGTTAC \\
\hline uc.66+ & TAATAATATGGGATGACTGGGG & TTGGTTGTTTTCTGTTTTGTGAT \\
\hline uc.80+ & TAATAAAAAGGAATCCATAAAAAAT & ATAATTACAACTCAGGTTACGCTT \\
\hline GAPDH & TGTTCGTCATGGGTGTGAA & ATGGCATGGACTGTGGTCAT \\
\hline
\end{tabular}

NanoDrop 2000 (Thermo Fisher Scientific, Inc.). The qualified total RNA was further purified by a RNeasy micro kit and RNase-free DNase set (both Qiagen GmbH, Hilden, Germany). Next, the total RNA was amplified, labeled and purified using the Affymetrix WT Amplication kit and the GeneChip WT Terminal Labeling kit (both Affymetrix; Thermo Fisher Scientific, Inc.) following the manufacturer's instructions. Each labeled cRNA $(1 \mu \mathrm{g})$ was fragmented by adding $5 \mu \mathrm{l} 10 \mathrm{X}$ blocking agent and $1 \mu \mathrm{l}$ of $25 \mathrm{X}$ fragmentation buffer, and then the mixture was heated at $60^{\circ} \mathrm{C}$ for $30 \mathrm{~min}$. Finally, $25 \mu 12 \mathrm{X} \mathrm{GE}$ hybridization buffer was added to dilute the labeled cRNA. Hybridization solution $(50 \mu \mathrm{l})$ was dispensed into the gasket slide and assembled into the lncRNA expression microarray slide. The slides were incubated for $17 \mathrm{~h}$ at $65^{\circ} \mathrm{C}$ in an Agilent hybridization oven (Agilent Technologies, Inc., Santa Clara, CA, USA). The hybridized arrays were washed with $1 \mathrm{X}$ washing buffer $(0.05 \mathrm{~mol} / 1 \mathrm{Tris} / \mathrm{HCl}, 0.15 \mathrm{~mol} / 1 \mathrm{NaCl}, 0.05 \%$ Tween 20, pH 7.6), and scanned using the Agilent DNA microarray scanner (catalog no. G2505C; Agilent Technologies, Inc.).

Agilent Feature Extraction software (version 11.0.1.1) was used to analyze acquired array images. Quantile normalization and subsequent data processing were performed using the GeneSpring GX v12.1 software package (Agilent Technologies, Inc.). After quantile normalization of the raw data, lncRNAs and mRNAs with at least 1 out of 2 samples flagged as 'Present' or 'Marginal' ('All Targets Value') were chosen for further data analysis. Differentially expressed lncRNAs and mRNAs between the two groups were identified through fold-change filtering: Absolute fold-change $\geq 2$, ANA+SKP-SC+heregulin-1 $\beta$-treated group vs. ANA+SKP-SC-treated group. Hierarchical clustering was performed using homemade scripts.

Reverse transcription-quantitative polymerase chain reaction $(R T-q P C R)$ analysis for the differentially expressed lncRNAs. Total RNA was reverse-transcribed into cDNA using the Reverse Transcription kit (Roche Diagnostics $\mathrm{GmbH}$, Mannheim, Germany). qPCR was performed on an Applied Biosystems 7500 instrument using a 20- $\mu$ l reaction volume containing $10 \mu \mathrm{l}$ of $2 \mathrm{X}$ light cycler $480 \mathrm{SYBR}-\mathrm{Green} \mathrm{I}$ Master (Roche Diagnostics $\mathrm{GmbH}$ ). Reactions were incubated in a 96 -well optical plate at $95^{\circ} \mathrm{C}$ for $10 \mathrm{~min}$, followed by 45 cycles of $95^{\circ} \mathrm{C}$ for $15 \mathrm{sec}$ and $60^{\circ} \mathrm{C}$ for $60 \mathrm{sec}$. Each sample was represented by at least three replicates for analysis. At the end of the PCR cycles, melting curve analysis was conducted to validate the PCR products. The primers for the specific amplification are listed in Table I. GAPDH was used as an internal control (20).

Cell transfection. siRNA (siRNA, 5'-AAUAAAAUUGUA AAAAAGGAA-3'; NC, 5'-ACGUGACACGUUCGGAGA ATT-3') was provided by Sangon Biotech (Shanghai, China). To induce hypoxic conditions in vitro, SCs previously incubated with heregulin- $1 \beta$ were cultured at $37^{\circ} \mathrm{C}$ in a humidified incubator with a mixture of $1 \% \mathrm{O}_{2}, 5 \% \mathrm{CO}_{2}$ and $94 \% \mathrm{~N}_{2}$ for 12 , 24 or $36 \mathrm{~h}$. Subsequent to $72 \mathrm{~h}$ of incubation, the SCs were transferred to new DMEM and transfected with siRNA targeted at lncRNA BC088327 (final concentration, $100 \mathrm{nM}$ ) with Lipofectamine $2000^{\circledR}$ (Invitrogen; Thermo Fisher Scientific, Inc.) according to the manufacturer's instructions. 
After transfection for $48 \mathrm{~h}$, the cells were harvested for cell viability, cell cycle and cell apoptosis assays.

Cell viability detection by Cell Counting Kit-8 (CCK-8) and EdU assay. The negative control or lncRNA BC088327 siRNA-transfected SCs were plated in separate 96-well plates (3 wells/group) with DMEM for $72 \mathrm{~h}$. For the CCK-8 assay, $10 \mu \mathrm{l}$ CCK-8 (Dojindo Molecular Technologies, Inc., Kumamoto, Japan) was then added to randomly selected wells in each group every $24 \mathrm{~h}$ (total time, $72 \mathrm{~h}$ ), and the viability of the cells was measured at $490 \mathrm{~nm}$ using an ELISA reader (BioTek Instruments, Inc., Winooski, VT, USA) according to the manufacturer's instructions. Each time-point was represented by at least three replicates. Upon completion of cell culture, the cell viabilities in different groups were further confirmed using the Click-iT EdU kit (Molecular Probes; Thermo Fisher Scientific, Inc.). The results were detected by flow cytometry, described as follows.

Cell cycle assays. The SCs $\left(1.0 \times 10^{6} /\right.$ well) were plated in 6 -well plates with DMSO $(10 \mu \mathrm{M})$ for $48 \mathrm{~h}$. Prior to the cell cycle assay, the cells were washed twice with ice-cold PBS and fixed in $70 \%$ ethanol at $4^{\circ} \mathrm{C}$ overnight. For RNA removal, the cells were be incubated with $10 \mathrm{mg} / \mathrm{ml}$ RNase A (Sigma-Aldrich; Merck KGaA, Darmstadt, Germany) at $37^{\circ} \mathrm{C}$ for $30 \mathrm{~min}$, and then stained with $50 \mathrm{mg} / \mathrm{ml}$ propidium iodide (PI; Sigma-Aldrich; Merck KGaA). Cell cycle distribution was assessed by flow cytometry (FC500; Beckman Coulter, Inc., Miami, FL, USA). Each group was represented by at least three replicates.

Quantification of apoptosis by flow cytometry. Apoptosis was assessed using Annexin V/fluorescein isothiocyanate(FITC)-PI measurement. The cells $\left(1 \times 10^{5}\right)$ were washed twice with PBS (pH 7.4) and resuspended in staining buffer containing $1 \mu \mathrm{g} / \mathrm{ml}$ PI and $0.025 \mu \mathrm{g} / \mathrm{ml}$ Annexin V-FITC (cat. no. 556547; BD Biosciences, Franklin Lakes, NJ, USA). Double-labeling was performed at room temperature for $10 \mathrm{~min}$ in the dark prior to the flow cytometry analysis. The stained cells were then analyzed with a flow cytometer (FC500; Beckman Coulter, Inc.). Each group were represented by at least three replicates.

Statistical analysis. Data are expressed as the mean \pm standard deviation and were analyzed using SPSS 13.0 software (SPSS, Inc., Chicago, IL, USA). An analysis of variance and a least significant difference post hoc test were performed, with $\mathrm{P}<0.05$ indicating a statistically significant difference.

\section{Results}

Differentially expressed lncRNAs screened by microarray assay. The results of the lncRNA microarray showed that a total of 8,124 lncRNAs were detected in the rat model, of which, 805 lncRNAs were significantly differentially expressed (absolute fold-change $\geq 2$, ANA+SKP-SC+heregulin-1 $\beta$-treated group vs. ANA+SKP-SC-treated group). It was found that 323 lncRNAs were upregulated and 482 lncRNAs were downregulated. The hierarchical cluster analysis of the lncRNA microarray data is shown in Fig. 1. The mRNA microarray identified a total of 13,112 mRNAs, in which 1,293 lncRNAs
Table II. Summary of differentially expressed lncRNAs and mRNAs between treatment and control groups.

\begin{tabular}{lccc}
\hline $\begin{array}{l}\text { Probe } \\
\text { class }\end{array}$ & $\begin{array}{c}\text { Differentially } \\
\text { expressed }\end{array}$ & Upregulated & Downregulated \\
\hline lncRNA & 805 & 323 & 482 \\
mRNA & 1293 & 603 & 690 \\
\hline
\end{tabular}

lncRNA, long non-coding RNA.

Table III. lncRNAs with significant differential expression.

\begin{tabular}{lll}
\hline lncRNA & Relative expression & Fold-change \\
\hline BC086339 & Upregulated & 5.9482925 \\
XR_007612 & Upregulated & 5.9529158 \\
uc.19+ & Upregulated & 6.2218258 \\
DQ203294 & Upregulated & 6.7717983 \\
BC088327 & Upregulated & 8.9564234 \\
uc.184+ & Upregulated & 7.7992154 \\
uc.75- & Upregulated & 8.860086 \\
S56464 & Upregulated & 8.8825432 \\
uc.366- & Upregulated & 9.6759103 \\
uc.173+ & Upregulated & 12.2055043 \\
uc.10- & Downregulated & 11.5705296 \\
uc.456- & Downregulated & 12.0019673 \\
uc.128- & Downregulated & 12.614861 \\
D26496 & Downregulated & 13.01382 \\
uc.298- & Downregulated & 13.4702367 \\
uc.28- & Downregulated & 13.8457471 \\
uc.325- & Downregulated & 13.8457471 \\
uc.299- & Downregulated & 13.8457471 \\
uc.66+ & Downregulated & 13.8457471 \\
uc.80+ & Downregulated & 15.2508305 \\
& & \\
\hline
\end{tabular}

lncRNA, long non-coding RNA.

were significantly differentially expressed (absolute fold-change $\geq 2$, ANA+SKP-SC+heregulin-1 $\beta$-treated group vs. ANA+SKP-SC-treated group), including 603 upregulated lncRNAs and 690 downregulated lncRNAs (Table II). Based on the fold-change data, 20 lncRNAs with an upregulated fold-change $>5$ and a downregulated fold-change $>10$ were screened by RT-qPCR analysis (Table III).

$R T$-qPCR analysis of the expression of the lncRNAs. Following the preliminary analysis of the results from the IncRNA profile, a total of 20 lncRNAs were analyzed by the RT-qPCR assay (Fig. 2). The results were normalized to a GAPDH control. The lncRNAs presented with similar expression tendencies as those in the microarray assay. Among them, the BC088327 and uc.75 exhibited the greatest change in expression compared with the other IncRNAs, and the extent of D26496 and uc.325 downregulation was markedly greater than that of the other IncRNAs. 

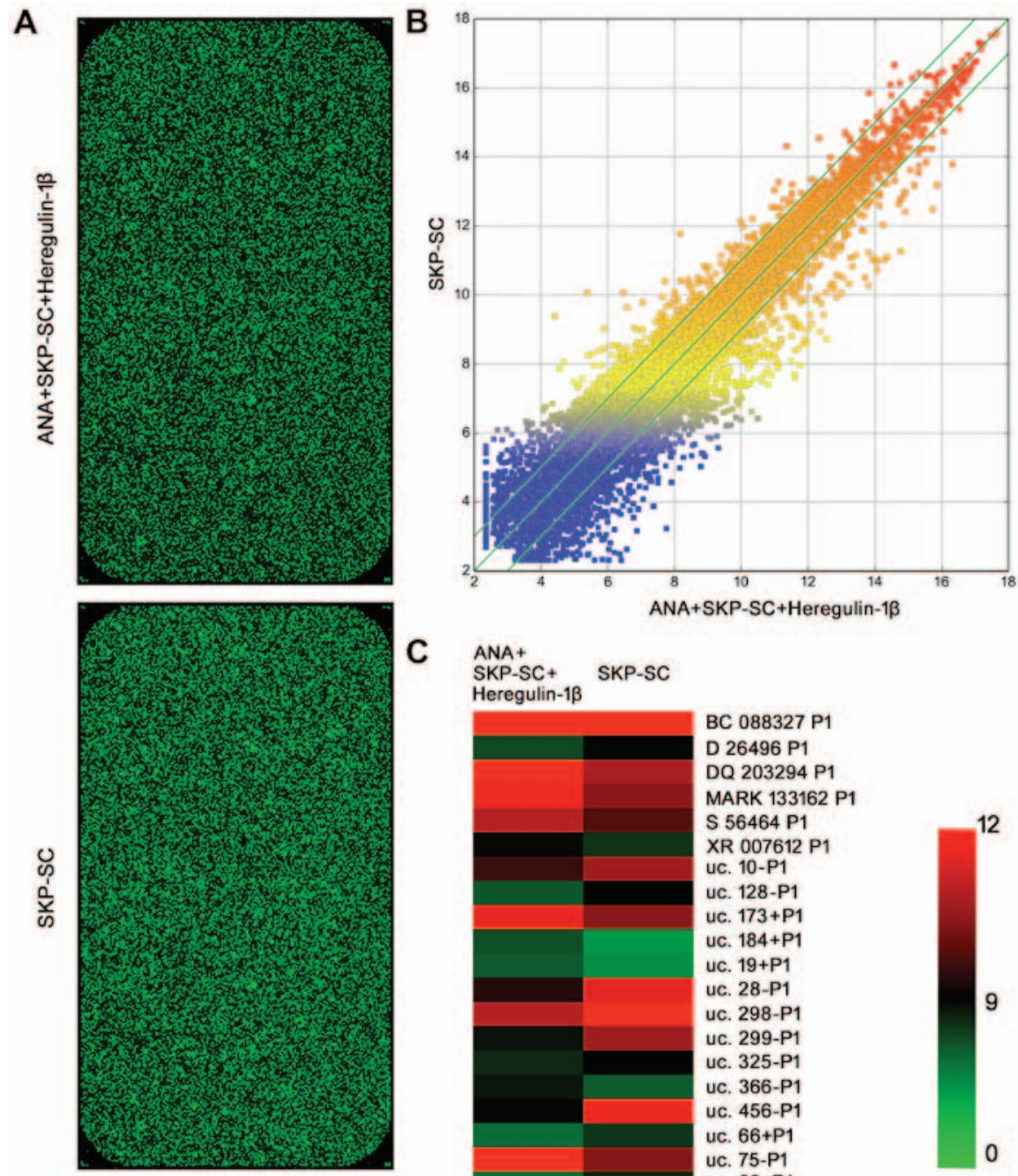

\section{ANA+}

SKP-SC+ SKP-SC
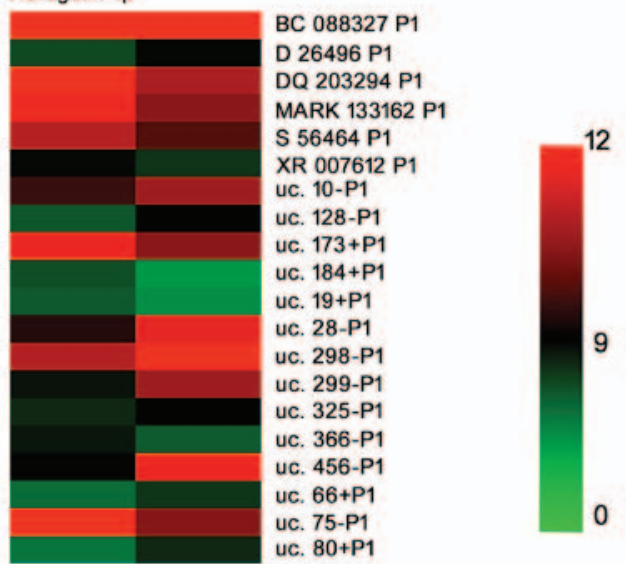

Figure 1. Treatment with heregulin-1 $\beta$ induces differentially expression of lncRNAs in rats with peripheral nerve injuries. (A) Representative images of microarray assays for the experimental group (ANA+SKP-SCs+heregulin-1 $\beta$-treated group) and the control group (ANA+SKP-SC-treated group). The lncRNAs that showed significant differential expression were obtained for further analysis. (B) Collinearity analysis results of microarray assays. (C) Hierarchical cluster analysis of lncRNA microarray data. lncRNA, long non-coding RNAs; SKP, skin-derived precursors; SC, Schwann cell; ANA, acellular nerve allograft.

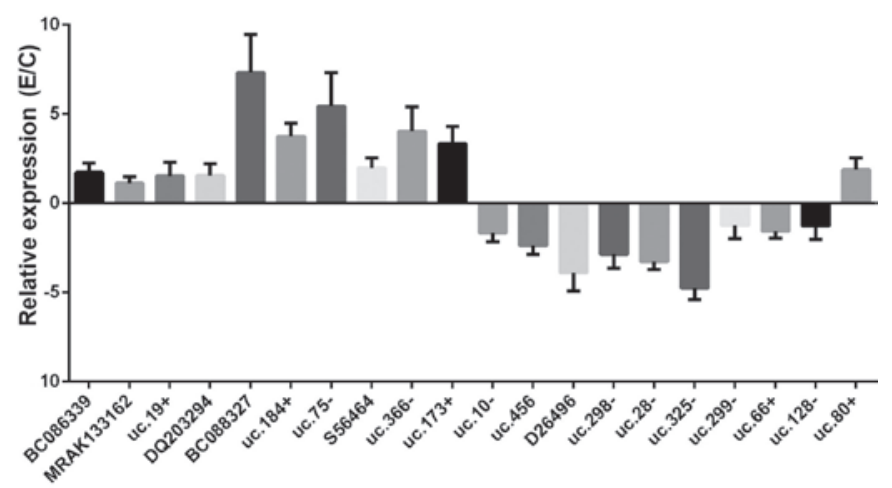

Figure 2. Verification of the differentially expressed lncRNAs by RT-qPCR. The 20 screened lncRNAs with $>5$-fold upregulation or $>10$-fold downregulation are listed. These lncRNAs were then further assessed by RT-qPCR analysis. The $2^{-\triangle \Delta C q}$ method was used for the comparison. E, experimental group; C, control group; lncRNA, long non-coding RNA; RT-qPCR, reverse transcription-quantitative polymerase chain reaction.

BC088327 serves important roles in nerve cell proliferation. To further study the functions of the differentially expressed

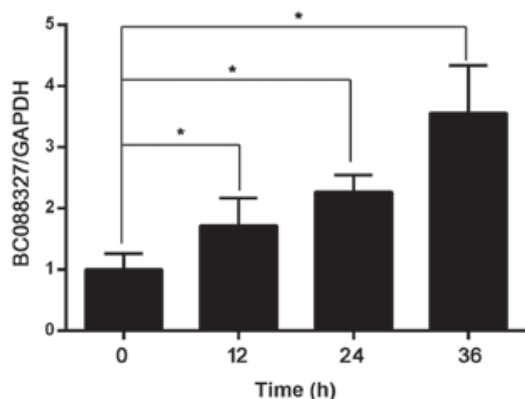

Figure 3. Expression level of long non-coding RNA BC088327 in Schwann cells under hypoxic conditions in the presence of heregulin- $1 \beta$ for different lengths of time. The expression of $\mathrm{BC} 088327$ was detected by reverse transcription-quantitative polymerase chain reaction. GAPDH was used as an internal control. An increasing expression level was exhibited across the whole period and reached the highest at $72 \mathrm{~h}\left({ }^{*} \mathrm{P}<0.05\right.$ and ${ }^{* *} \mathrm{P}<0.01$ vs. $\left.0 \mathrm{~h}\right)$.

lncRNAs, a hypoxia-induced SC model was induced. The results of RT-qPCR showed an increased expression level of lncRNA BC088327 with hypoxic exposure time in the presence of heregulin-1 $\beta$ (Fig. 3), while other lncRNAs did not response 
A

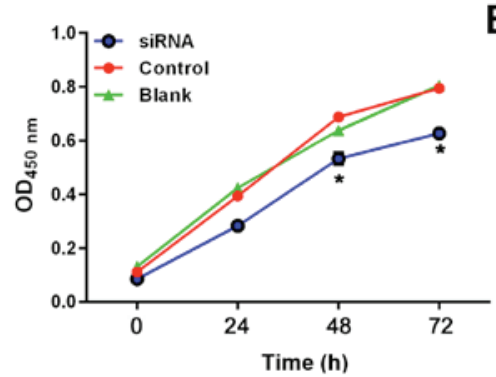

C

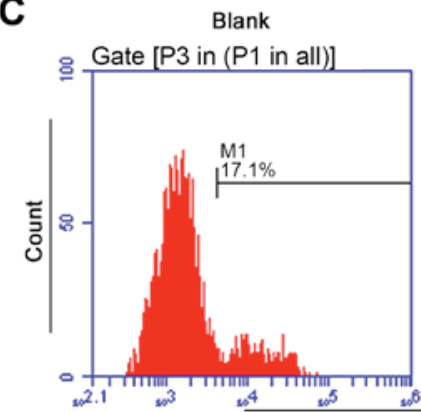

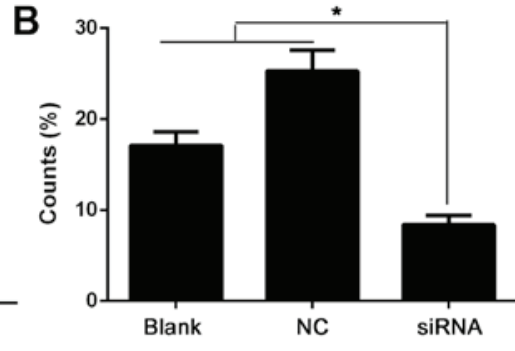
O. Gate [P3 in (P1 in all)]

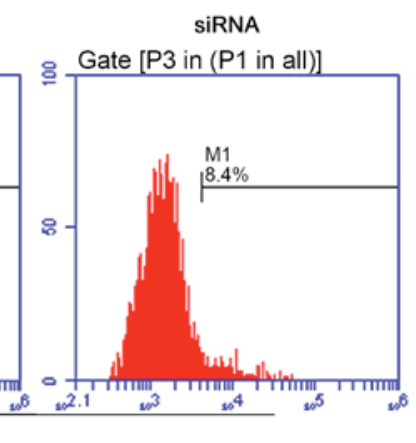

Figure 4. Cell viability in Schwann cells under hypoxic conditions in the presence of heregulin-1 $\beta$ for different lengths of time. The OD values increased over time in all the groups. The siRNA group showed lower cellular viability than the control and blank groups during the whole period ("P<0.05). (A) Cell viability detected by CCK-8 assay. (B and C) Cell viability detected by EdU assay. OD, optical density; siRNA, small intefering RNA; NC, negative control.

A

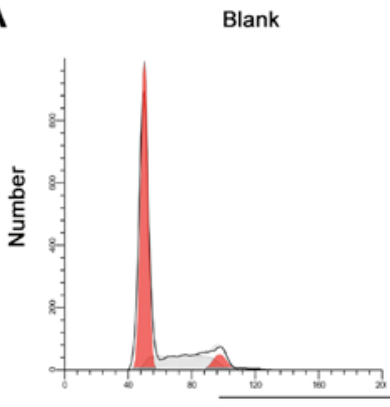

NC

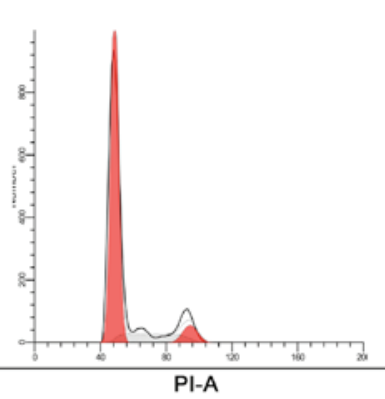

SiRNA

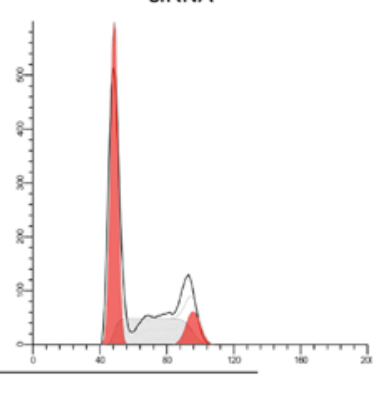

C

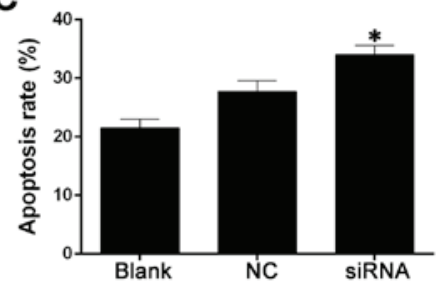

D

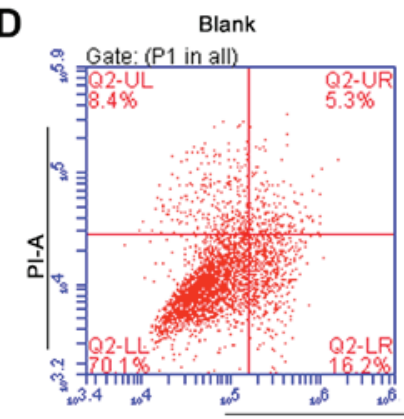

B

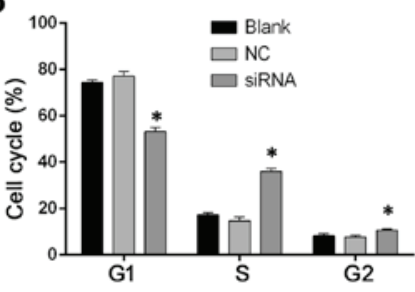

NC

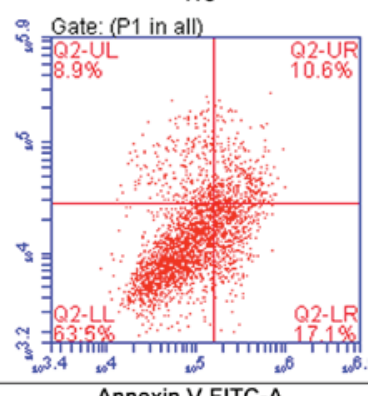

SiRNA

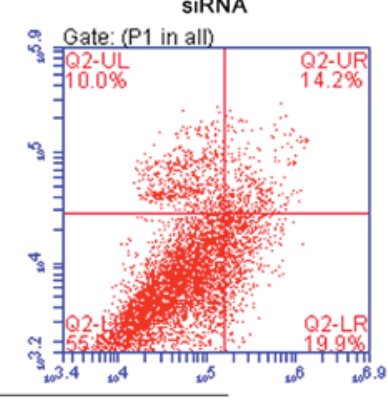

Figure 5. Cell cycle assay and apoptosis in Schwann cells under hypoxic conditions in the presence of heregulin-1 $\beta$ for different lengths of time were detected by flow cytometry assay. It was shown that the cell proliferation was increased in the experimental group and that more cells were found in G2/M and S phases, compared with that in the control group. (A and B) Flow cytometry analysis of cell cycle distribution of different groups ("P $<0.05$ vs. control). (C and D) Flow cytometric analysis of cell apoptosis of different groups analysis, Annexin V/PI analysis was performed to determine cell apoptosis in the indicated groups ("P<0.05 vs. control). siRNA, small intefering RNA; NC, negative control; PI, propidium iodide; FITC, fluorescein isothiocyanate. 
to hypoxia in the presence of heregulin-1 $\beta$ (data not shown). For detecting the role of BC088327 in cell viability, siRNA that targeted BC088327 was designed and transfected into the SCs, and then the CCK-8 stain assay was performed (Fig. 4A). Together with EdU staining, these results showed that transfection with siRNA significantly suppressed the cell viability, indicating that upregulation of BC088327 may be associated with the activation of cellular proliferation in the presence of heregulin-1 $\beta$ (Fig. 4B and C). Cell cycle analysis was also performed using a flow cytometry assay (Fig. 5A and B). Consistent with the CCK-8 assay, knockdown of BC088327 increased the cell proportion distributed in the $\mathrm{S}$ and $\mathrm{G} 2 / \mathrm{M}$ phases in hypoxic SCs in the presence of heregulin-1 $\beta$. Moreover, the apoptotic rate of cells transfected with BC088327 siRNA were significant augmented compared with that in the blank and NC groups (Fig. 5C and D) $(\mathrm{P}<0.05)$. Taken together, these results suggested that the function of $\mathrm{BC} 088327$ was likely to be synergic with heregulin-1 $\beta$, which promoted peripheral nerve repair through induction of cell proliferation.

\section{Discussion}

As molecules that are involved in various processes associated with diseases, oncogenesis and metabolism (21), lncRNAs have received increasing attention over the past decade. However, even with the emerging focus on IncRNAs, the mechanisms behind their functions remain poorly explored $(22,23)$. Currently, information on the function of lncRNAs mainly focuses on their roles in the regulation of gene expression at multiple levels, including epigenetic modification, and transcriptional and post-transcriptional regulation $(24,25)$. The involvement of lncRNAs in the regulation of peripheral nerve injury and the repair process, and the role of lncRNAs in the nervous system have been studied, however, the molecular mechanism was not clear $(26,27)$.

In the present study, multiple lncRNAs were shown to be differentially expressed in rats with peripheral nerve injuries that were treated with ANA plus SKPs-SCs and heregulin-1 $\beta$ when compared with the control group (ANA plus SKPs-SCs). Among all the differentially expressed lncRNAs, BC088327 was upregulated to the largest extent, and knockdown of the lncRNA induced cell apoptosis and cell cycle arrest in hypoxic SCs with the presence of heregulin-1 $\beta$. It is well known that heregulin- $1 \beta$ is a member of the neuregulin family, which are polypeptide ligands of ErbB tyrosine kinase receptors. Members of this family serve essential roles in the transmission of growth and differentiation signals in neuronal development (11). Since soluble heregulin-1 $\beta$ can specifically activate mitogen-activated protein kinase and protein kinase $B$ pathways, it is implied to regulate the development, growth and repair of the tissues (28-30). In our previous study (12), it was demonstrated that heregulin- $1 \beta$ promotes the outcome of reinnervation by ANA+SKP-SC therapy. In the present study, it was found that IncRNA BC088327 was upregulated in the SKPs-SC plus ANA+heregulin-1 $\beta$ group. Moreover, in hypoxic SCs, silencing of BC088327 is likely to play a synergic role with heregulin-1 $\beta$, as knockdown of BC088327 suppressed the cell proliferation through the induction of cell cycle arrest and cell apoptosis. However, the underlying mechanism involved in the function of BC088327 may be complicated. Based on a microarray assay of the mRNA profile, in the experimental group, the cytokines involving inflammatory signal molecules, including interleukin (IL)-1 $\beta$, tumor necrosis factor- $\alpha$ and IL-6, were increased (all fold-changes $>2$ ). All these cytokines can contribute to the activation of downstream cell apoptosis $(21,31,32)$. Nevertheless, solid evidence in the present study also showed that extracellular signal-regulated kinase (ERK) and c-Myc were upregulated in the experimental group (all fold-changes $>2$ ). Contrary to the effect of cytokines, c-Myc is an important mediator of the cell cycle, and increased ERK and c-Myc levels will lead to cell proliferation and differentiation that is consistent with the functions of heregulin-1 $\beta(33,34)$. Although the present results indicated a synergic interaction between $\mathrm{BC} 088327$ and heregulin-1 $\beta$, the exact mechanism through which BC088327 exerted its protective function on peripheral nerves requires further comprehensive investigation.

With the exception of BC088327, certain other differentially expressed lncRNAs may also be associated with neuronal repair, including lncRNAs that have been previously reported to be associated with cell proliferation or differentiation in other models $(35,36)$. For example, the upregulated lncRNA uc.173 induced by heregulin- $1 \beta$ is able to inhibit the neuronal apoptosis in the hippocampus tissue model (37). In the study by Yao et al, it was indicated that silencing of uc. 217 expression could significantly promote neurite outgrowth in cultured dorsal root ganglion neurons (38). However, the functions of the majority of the differentially expressed lncRNAs detected in the present study remain unknown. Further studies on these IncRNAs and their downstream effectors are required to unveil the structure of the regulation network of lncRNAs.

In conclusion, the differentially expressed lncRNABC088327 serves an important role in regulating cell proliferation during the process of nerve repair. Considering its synergic action with hegerulin-1 $\beta$, IncRNA BC088327 can be either employed as a biomarker for detecting the extent of the nerve injury or as a novel therapeutic target for promotion of nerve repair. For such purposes, a better understanding of the functions of lncRNAs, such as the regulatory network and mechanism involved in their effect, should be further expanded upon in the future.

\section{Acknowledgements}

This study was supported by funds from the Shanghai Municipal Commission of Health and Family Planning (grant no. 2014-399).

\section{Competing interests}

The authors declare that they have no competing interests.

\section{References}

1. Cattin AL and Lloyd AC: The multicellular complexity of peripheral nerve regeneration. Curr Opin Neurobiol 39: 38-46, 2016.

2. Trehan SK, Model Z and Lee SK: Nerve repair and nerve grafting. Hand Clin 32: 119-125, 2016.

3. Giger RJ, Hollis ER II and Tuszynski MH: Guidance molecules in axon regeneration. Cold Spring Harb Perspect Biol 2: a001867, 2010.

4. Guest J, Santamaria AJ and Benavides FD: Clinical translation of autologous Schwann cell transplantation for the treatment of spinal cord injury. Curr Opin Organ Transplant 18: 682-689, 2013. 
5. Tabakow P, Raisman G, Fortuna W, Czyz M, Huber J, Li D, Szewczyk P, Okurowski S, Miedzybrodzki R, Czapiga B, et al: Functional regeneration of supraspinal connections in a patient with transected spinal cord following transplantation of bulbar olfactory ensheathing cells with peripheral nerve bridging. Cell Transplant 23: 1631-1655, 2014.

6. Walsh SK, Kumar R, Grochmal JK, Kemp SW, Forden J and Midha R: Fate of stem cell transplants in peripheral nerves. Stem Cell Res (Amst) 8: 226-238, 2012.

7. Guertin AD, Zhang DP, Mak KS, Alberta JA and Kim HA: Microanatomy of axon/glial signaling during Wallerian degeneration. J Neurosci 25: 3478-3487, 2005.

8. Walsh S and Midha R: Practical considerations concerning the use of stem cells for peripheral nerve repair. Neurosurg Focus 26 E2, 2009.

9. Liu GB, Cheng YX, Feng YK, Pang CJ, Li Q, Wang Y, Jia H and Tong XJ: Adipose-derived stem cells promote peripheral nerve repair. Arch Med Sci 7: 592-596, 2011.

10. Khuong HT, Kumar R, Senjaya F, Grochmal J, Ivanovic A, Shakhbazau A, Forden J, Webb A, Biernaskie J and Midha R Skin derived precursor Schwann cells improve behavioral recovery for acute and delayed nerve repair. Exp Neurol 254 $168-179,2014$

11. Mei L and Xiong WC: Neuregulin 1 in neural development, synaptic plasticity and schizophrenia. Nat Rev Neurosci 9: 437-452, 2008

12. Wang H, Wu J, Zhang X, Ding L and Zeng Q: Study of synergistic role of allogenic skin-derived precursor differentiated Schwann cells and heregulin-1 $\beta$ in nerve regeneration with an acellular nerve allograft. Neurochem Int 97: 146-153, 2016.

13. Verrier JD, Semple-Rowland S, Madorsky I, Papin JE and Notterpek L: Reduction of Dicer impairs Schwann cell differentiation and myelination. J Neurosci Res 88: 2558-2568, 2010.

14. Arthur-FarrajPJ, Morgan CC, Adamowicz M, Gomez-Sanchez JA Fazal SV, Beucher A, Razzaghi B, Mirsky R, Jessen KR and Aitman TJ: Changes in the coding and non-coding transcriptome and DNA methylome that define the schwann cell repair phenotype after nerve injury. Cell Rep 20: 2719-2734, 2017.

15. Pan B, Zhou HX, Liu Y, Yan JY, Wang Y, Yao X, Deng YQ Chen SY, Lu L, Wei ZJ, et al: Time-dependent differential expression of long non-coding RNAs following peripheral nerve injury. Int J Mol Med 39: 1381-1392, 2017.

16. Zhou S, Ding F and Gu X: Non-coding RNAs as emerging regulators of neural injury responses and regeneration. Neurosci Bull 32: 253-264, 2016

17. Schmitt AM and Chang HY: Long noncoding RNAs in cancer pathways. Cancer Cell 29: 452-463, 2016.

18. Rühle F and Stoll M: Long non-coding RNA databases in cardiovascular research. Genomics Proteomics Bioinformatics 14: 191-199, 2016.

19. Toma JG, Akhavan M, Fernandes KJ, Barnabé-Heider F, Sadikot A, Kaplan DR and Miller FD: Isolation of multipotent adult stem cells from the dermis of mammalian skin. Nat Cell Biol 3: 778-784, 2001

20. Livak KJ, Schmittgen TD: Analysis of relative gene expression data using real-time quantitative PCR and the 2(-Delta Delta C(T)) Method. Method 25: 402-408, 2001.

21. Takayama $\mathrm{K}$ and Inoue S: The emerging role of noncoding RNA in prostate cancer progression and its implication on diagnosis and treatment. Brief Funct Genomics 15: 257-265, 2016.
22. Geisler S and Coller J: RNA in unexpected places: long non-coding RNA functions in diverse cellular contexts. Nat Rev Mol Cell Biol 14: 699-712, 2013.

23. Yang L, Froberg JE and Lee JT: Long noncoding RNAs: fresh perspectives into the RNA world. Trends Biochem Sci 39: 35-43, 2014.

24. Wilusz JE, Sunwoo H and Spector DL: Long noncoding RNAs: functional surprises from the RNA world. Genes Dev 23: 1494-1504, 2009

25. Taft RJ, Pang KC, Mercer TR, Dinger M and Mattick JS: Non-coding RNAs: regulators of disease. J Pathol 220: 126-139, 2010.

26. Knauss JL and Sun T: Regulatory mechanisms of long noncoding RNAs in vertebrate central nervous system development and function. Neuroscience 235: 200-214, 2013.

27. Ng SY, Bogu GK, Soh BS and Stanton LW: The long noncoding RNA RMST interacts with SOX2 to regulate neurogenesis. Mol Cell 51: 349-359, 2013.

28. Yang SH, Sharrocks AD and Whitmarsh AJ: MAP kinase signalling cascades and transcriptional regulation. Gene 513: 1-13, 2013.

29. Gu Y, Xue C, Zhu J, Sun H, Ding F, Cao Z and Gu X: Basic fibroblast growth factor (bFGF) facilitates differentiation of adult dorsal root ganglia-derived neural stem cells toward Schwann cells by binding to FGFR-1 through MAPK/ERK activation. J Mol Neurosci 52: 538-551, 2014.

30. Awasthi S and Hamburger AW: Heregulin negatively regulates transcription of ErbB2/3 receptors via an AKT-mediated pathway. J Cell Physiol 229: 1831-1841, 2014.

31. Gierut JJ, Wood LB, Lau KS, Lin YJ, Genetti C, Samatar AA, Lauffenburger DA and Haigis KM: Network-level effects of kinase inhibitors modulate TNF- $\alpha$-induced apoptosis in the intestinal epithelium. Sci Signal 8: ra129, 2015.

32. Gurung P and Kanneganti TD: Novel roles for caspase-8 in IL-1 $\beta$ and inflammasome regulation. Am J Pathol 185: 17-25, 2015.

33. Bueno MJ and Malumbres M: MicroRNAs and the cell cycle. Biochim Biophys Acta 1812: 592-601, 2011.

34. Chen Y, Lin C, Liu Y and Jiang Y: HMGB1 promotes HCC progression partly by downregulating p21 via ERK/c-Myc pathway and upregulating MMP-2. Tumour Biol 37: 4399-4408, 2016.

35. Chen SX, Yin JF, Lin BC, Su HF, Zheng Z, Xie CY and Fei ZH: Upregulated expression of long noncoding RNA SNHG15 promotes cell proliferation and invasion through regulates MMP2/MMP9 in patients with GC. Tumour Biol 37: 6801-6812, 2016

36. Zhang J, Yao T, Wang Y, Yu J, Liu Y and Lin Z: Long noncoding RNA MEG3 is downregulated in cervical cancer and affects cell proliferation and apoptosis by regulating miR-21. Cancer Biol Ther 17: 104-113, 2016.

37. Nan A, Zhou X, Chen L, Liu M, Zhang N, Zhang L, Luo Y, Liu Z, Dai L and Jiang Y: A transcribed ultraconserved noncoding RNA, Uc.173, is a key molecule for the inhibition of lead-induced neuronal apoptosis. Oncotarget 7: 112-124, 2016.

38. Yao C, Wang J, Zhang H, Zhou S, Qian T, Ding F, Gu X and Yu B: Long non-coding RNA uc. 217 regulates neurite outgrowth in dorsal root ganglion neurons following peripheral nerve injury. Eur J Neurosci 42: 1718-1725, 2015. 